\title{
A Flight-Test Methodology for Identification of an Aerodynamic Model for a V/STOL Aircraft
}

Ralph E. Bach, Jr., and B. David McNally

(AASA-TM-100067) A FIIGHT-TEST METHODOLOGY ECE ILENIIFICATICN OF AN LEFCIYAAHIC MCDEL FCR A V/STOL AILCEAFT (NASA) 12 p CSCL $01 C$

March 1988 


\section{A Flight-Test Methodology for Identification of an Aerodynamic Model for a V/STOL Aircraft}

Ralph E. Bach

Jr., B. David McNally

Ames Research Center, Moffett Field, California

March 1988

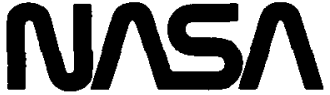

National Aeronautics and

Space Administration 
A FLIGHT-TEST METHODOLOCY FOR IOENTIFICATION OF AN AERODYNAMIC MODEL FOR A V/STOL AIRCRAFT

Ralph E. Bach, Jr.

B. David McNally

NASA Ames Research Center, Moffett Field, CA 94035, USA

Abstract. This paper describes a flight-test methodology for developing a data base to be used to identify an aerodynamic model of a vertical and short takeoff and landing ( $V / S T O L)$ fighter alrcraft. The aircraft serves as a test bed at Anes for ongoing research in advanced V/STOL control and display concepts. The flight envelope to be modeled includes hover, transition to conventional flight and back to hover, STOL operation, and normal cruise. Although the aerodynamic model is highly nonlinear, it has been formulated to be linear in the parameters to be Identified. Motivation for the flight-test methodology advocated in this paper is based upon the choice of a linear least-squares method for model identiflcation. The paper covers elements of the methodology from maneuver design to the completed data base. Major emphasis is placed on the use of state estimation with tracking data to ensure consistency among maneuver variables prior to their entry into the data base. The design and processing of a typical maneuver will be lllustrated.

Keywords. Flight testing; data consistency analysis; aerodynamic modeling.

\section{INTRODUCTION}

Ames is conducting a flight research program on guidance, control, and display concepts for V/STOL aircraft. The program is directed towards extending $V / S T O L$ capability to include flight operations aboard small ships in adverse weather. The test bed for this research is a $Y A V-8 B$ aircraft, a prototype of the currently operational AV- $8 B$ Harrier. The Harrier is a subsonic, vectored-thrust, $V / S T O L$ fighter aircraft; its engine nozzles can be rotated from $0^{\circ}$ for forward flight to somewhat greater than $90^{\circ}$ for hover and vertical flight. Compressor air is piped to the extremities of the aircraft for attitude control in hover and low-speed flight. The V/STOL Research Aircraft (VSRA) is shown in Fig. 1. The purpose of this paper is to describe a flight-test methodology for developing a data base that will be used to identify a full-envelope VSRA aerodynamic model. The model will be used to update and improve an existing VSRA simulation (Anderson and Bunnell, 1985) which will aid in design of guidance, control, and display systems for the aircraft.

The goal of acquiring a data base matched to a least-squares (regression) identification task has motivated the flight-test methodology outlined in Fig. 2. Because regression methods are computationally simple, careful attention can be given to the structuring of an accurate and physically meaningful model. The VSRA data base consists of a set of individual 3-5 min flight-test maneuvers that together cover the complete flight envelope. The records from each maneuver are sufficient to construct time histories of the forces and moments that comprise the aerodynamic model, and include time histories of all relevant aircraft state and control varlables. Long (15-30 min) records, consisting of concatenated segments from several maneuvers, will be used to identify parameters in each model equation. The important aspects of the preflight planning, flight testing, and postflight processing phases necessary to acquire the data base $w 111$ be covered in this paper. The modeling of VSRA aerodynamics $w i l 1$ be reported elsewhere.

A key element in this methodology is the use of state estimation in the processing of each maneuver before its entry to the data base. Flight data often contain significant errors which should be corrected before the data are used for model identification. Furthermore, direct measurements of some dynamlc variables may be unreliable or unavallable. These problems can be solved by the analytical method known as state estimation. Application of the method to aircraft flight data is possible because the forces and resulting motions of an aircraft along its flightpath are related by well-known equations of motion. The equations are used to produce estimates of force and motion variables that are compared with corresponding measurement time histories, usually with iterations, until suitable "fits" are obtalned.

The first application of state estimation to postflight data analysis can probably be attributed to otto Gerlach in the 1960 s at the Delft Technological University, the Netherlands. This early contribution (Gerlach, 1966), called "flightpath reconstruction," was primarily concerned with accurate determination of angle of attack, pitch angle, and vehicle velocity during dynamic maneuvers. These "states" were obtained by integrating functions of measurements from the pitch-rate gyro and normal and longitudinal accelerometers. 
Initial conditions and blas terms were determined from airspeed and altitude at the steady-state end points of the maneuver. The resulting "snoothed" time histories were then used as a basis for subsequent parameter-identiflcation studies.

In this country, Wingrove (Wingrove, 1973) at NASA was an early advocate of state estimation for flightpath reconstruction. Over the past few years, work in this fleld has been evolving toward the use of more complete models, the development of more sophisticated algorithms, and the treatment of more difficult applications (Bach and Wingrove, 1985). State estimation methods are now used by many flight-test groups (Stalford and Ramachandran, 1978; Klein and Schiess, 1977; Hansen, 1979; Sri-Jayantha and Stengel, 1983). Once a consistent, smoothed set of time histories is obtained from the data, other analyses, such as aerodynamic model identification, are readily performed. The use of state estimation prior to modeling to correct the USRA data and to provide estimates of unmeasured variables is illustrated in this paper.

The paper proceeds as follows: the next section describes the planning and design of test maneuvers needed to cover the flight envelope. The rollowing sections discuss the data acquisition procedure used to generate the raw data records, and the techniques used to process those records. Then a section is presented that shows how state estimation is applied to the analysis of VSRA flight data. (The basic algorithm is given in the Appendix.) The last sections cover the calculation of aerodynamic forces and moments, and 11lustrate the procedure with a typical USRA maneuver.

\section{PREFLIGHT PLANNING}

The USRA aerodynamic model must represent the three body forces and three moments over a flight envelope that includes hover, transition to forward flight and back to hover, as well as short takeoff and landing (STOL) operation and normal cruise. The resulting model will be strongly nonlinear with respect to aircraft state and control variables such as angles of attack and sideslip, Mach number, nozzle angle, and power setting. The model nonlinearities can be conveniently expressed with functions that are 1 inear in the parameters to be identified (McNally, 1986; Anderson, 1986; Anderson and Hansen, 1987). A linear least-squares (regression) method (Klein and Batterson, 1983; Draper and Smith, 1981; Klein and Batterson, 1986) is well-suited to ident1fy a highly nonlinear model that is linearly parameterized.

The data base required for least-squares aerodynamic model identification can be obtained quite efficiently. Because the model is nonlinear, it is not necessary to maintain trim during a maneuver. In addition, because a regression procedure will be used to identify the model, large amounts of data may be processed. The order in which data samples are entered into the procedure is not significant, since an "equation-error" method does not require solution of the differential equations of aircraft motion. Accordingly, each flight-test maneuver has been designed to yield large changes in state and control variables while covering a (nearly) closed course within 5 min under continuous radar surveillance. The raw data base consists of as many longitudinal, lateral, and transitional (to and from hover) maneuvers as are necessary to cover the flight envelope. After processing, model sections may be identifled using long (15-30 min) records, each consisting of concatenated segments from several maneuvers.

One characteristic that sets the USRA apart from conventional aircraft is that it exhibits signiflcant power-induced aerodynamic effects when the nozzles are not in the full-aft position. These are largest during transition from hover to for ward flight (and back to hover), and during periods of low-speed flight. Standard V/STOL procedures were used to provide data for identification of power-induced aerodynamics. One of these procedures, a short takeoff-slow landing maneuver, is outlined on the flight-test card shown in Fig. 3. In this maneuver, the ground roll begins with nozzles at $10^{\circ}$. At $V_{r}$ (indicated air speed) the nozzles are rotated to an angle $\theta_{r}$ (in the example for this paper, $v_{r}=50$ knots and $\theta_{r}=55^{\circ}$ ). Shortly after liftoff, the nozzles are rotated to the full-aft position. For the slow-landing portion, nozzles are rotated to $40^{\circ}$ just before the final turn, and during the final approach are further rotated to $60^{\circ}$.

Other maneuvers were specifically designed to excite large changes in longitudinal variables from several nominal trim points. In each of these maneuvers, nozzle angle, rlap deflection, and power are held constant while the stabilator is varled to obtain changes in angle of attack and pitch rate. The maneuver includes "stick pumping," an "alpha ladder," and a "wind-up" turn. Near the end of the maneuver, power is added to return to the nominal trim point. Note that a considerable varlation in Mach number may be expertenced during the maneuver. Another set of maneuvers was designed to excite large changes in the lateral-model variables (angle of sideslip, yaw rate, and roll rate). All maneuvers were performed without "stability augmentation" to ensure a full range of vehicle response activity. V/STOL procedures were performed in and out of ground effect.

\section{DATA ACQUISITION}

The USRA measurement system is equipped with a 10-bit digital data acquisition and telemetry (TM) system. A pulse-code modulation format is used to encode 156 mainframe channels sampled at $120 \mathrm{~Hz}$ and 160 subframe channels sampled at $30 \mathrm{~Hz}$. Before encoding, each analog channel is passed through a third-order Butterworth anti-aliasing filter with its cutoff frequency set at one-fifth of the channel sampling rate. After encoding, all fight data are transmitted to a ground station where they are recorded. A partial list of onboard measurements, those necessary for aerodynamic model identification, is given in Table 1.

Flight tests of the USRA were performed at the NASA test racility located at Crows Landing California. The facility control room, which has a clear view of the runway ard hover pad, is equipped with five eight-channel strip-chart 
recorders and three color monitors for real-time display of the TM data. Two on-site radar systems are available to provide continuous tracking of test aircraft position. (A laser tracking system is used for all hover maneuvers.) During flight test, TM data from the VSRA onboard system are downlinked and merged at the facility with range, bearing, and elevation data frow the tracking systems, and then recorded.

\section{PRELIMINARY PROCESSING}

Following real-time acquisition of data during flight test, each recorded maneuver, with instrument calibrations added, is converted to engineering units and made available to researchers as a raw flight-data flle. The first program in the postflight processing system is called PRODAT (PROcess DATa). This program reads the raw file and creates a "processed" file of selected channels. Processing begins by removing wild points from the records. Several options are available, but one effective (and time-consuming) method is to pass each record through a "moving window." Points that fall outside the window are considered wild, and are tagged but not removed. When all wild points in a record have been tagged, the record is passed through a zero-phase-shift, lowpass digital fliter to obtain an Interpolated time history free of wild points. After interpolation, the data rate can be reduced to a submultiple of the mainframe sampling frequency. The filter cutof frequency is set at one-half the final data rate desired. That data rate was chosen to be $20 \mathrm{~Hz}$ for all VSRA maneuvers.

Each channel processed from a maneuver raw-data file is stored in a processed flight-data flle set up for that maneuver. The analyst may use a program called DSPDAT (DiSPlay DATa) to interactively select processed data channels for plotting in either $x-y$ or strip-chart format. An $x-y$ cross plot, for example, wight display Mach number plotted against angle of attack. Such plots offer a convenient way to evaluate how well the flight envelope has been covered during a maneuver. It is unlikely that a single maneuver will provide enough variation in alrcraft state and control variables to Identify all model terms: the analyst may also use this program to create a "map" file, which will contain addresses of time segments selected from several processed maneuvers. This file can later be used to concatenate the selected segments to create a long record suitable for model identification.

\section{STATE ESTIMATION}

The next step in the processing of each maneuver is to apply SMACK (SHoothing for AirCraft Kinematics), a state-estimation program developed at Ames Research Center (Bach, 1977; Bach, 1982) to check data consistency and derive unmeasured varlables. The SMACK algorithn uses a six-degree-of-freedom kinematic model to fit aircraft measurement time histories. The algorithm is described in the Appendix. A dlagram that defines the aircraft state and measurement models used in SMACK is shown in $81 \mathrm{~g}$. 4. Note that the state model is linear; all nonlinearities are found in the measurement model. Choice of a set of state variables and forcing functions consisting of Euler angles $(\bullet, \theta, \psi)$, earth positions $(x, y, h)$, earth winds $\left(w_{x}, w_{y}, w_{h}\right)$, and their time derlvatives leads to a linear state model. Note that the block symbols to the left of the vertical dashed line represent integrators.

A11 nonlinearities associated with aircraft kinematics appear in the measurement model. For example, the alrcraft angular velocities $(p, q, r)$ are expressed in terms of the states as

$$
\begin{aligned}
& p=\dot{i}-\dot{s i n} \theta \\
& q=\dot{\theta} \cos \phi+i \sin \cos \theta \\
& r=-\dot{\theta} \sin \phi+i \cos \phi \cos \theta
\end{aligned}
$$

Equations (1) are computed in the block of Fig. 4 labeled with a script $R$. Calculations of aircraft body-axis velocities $(u, v, w)$ and specific forces $\left(a_{x}, a_{y}, a_{z}\right.$ ) require the usual transformations from earth to body coordinates (Gainer and Hoffman, 1972) which are performed in the blocks labeled with a script $L$. Radar variables $R$ (slant range), B (bearing angle), and $E$ (elevation angle), which are given by

$$
\begin{aligned}
& R=\left[\left(x-x_{a}\right)^{2}+\left(y-y_{a}\right)^{2}+\left(h-h_{a}\right)^{2}\right]^{1 / 2} \\
& B=\tan ^{-1}\left[\left(y-y_{a}\right) /\left(x-x_{a}\right)\right] \\
& E=\sin ^{-1}\left[\left(h-h_{a}\right) / R\right]
\end{aligned}
$$

where $\left(x_{a}, y_{a}, h_{a}\right)$ is the antenna location, are calculated in the block labeled with a script $P$. If the measurement set includes static and total pressures, and total temperature, along with the air-rlow angles, the measurement model can provide estimates of aerodynamic variables $P$ (pressure ratio), $V$ (airspeed), a (angle of attack), and $B$ (sidesilp angle), from the relations (Dunlap and Porter, 1971)

$$
\begin{aligned}
& P=\left(1-v^{2} / 7 R T\right)^{-3.5} ; \quad v=\left(u^{2}+v^{2}+w^{2}\right)^{1 / 2} \\
& a=\tan ^{-1}(w / u) ; \quad B=\sin ^{-1}(v / v)
\end{aligned}
$$

where $R$ is the gas constant and $T$ is total temperature. These are calculated in the block labeled with script $A$. When air data measurements are included in the SMACK estimation procedure, the winds along the flightpath are also estimated. It is important that independent static pressure and air-flow angle corrections be available prior to a data-consistency analysis (Franklin, 1987).

\section{FORCE AND MOMENT CALCULATIONS}

The aerodynamic forces and moments acting on the VSRA during flight are determined as the difference between the total forces and moments, and engine forces and moments. Here the term "engine" includes the reaction control system as well as the main nozzles. The engine forces and moments are calculated (offline) by a program called ENCAL (ENgine CALculations). ENCAL uses a nominal propulsion model of the VSRA Pegasus engine (YF402-RR-404) (Anon., 1983). Fan dynamics are not included in this version, since fan speed is 
measured in flight. It should be noted that the propulsion model provides only thrust forces and moments. Any power-Induced aerodynamic effects are to be included in the VSRA aerodynamic model.

Inputs to the ENCAL routine Include all the airdata, reaction-control, engine, and weight measurements 11sted in Table 1 . Outputs to the processed flight-data file are the 3 body-axis components of engine forces and moments. ENCAL also calculates alrcraft welght and inertlas, and the variation in center-of-gravity location. These variables are added to the processed-data file. It should be emphasized that the aerodynamic model to be identified from flight data can only be as accurate as the engine model. A fully instrumented Pegasus engine has recently been installed on the VSRA, and the engine model will be validated after the next set of flight tests.

Total USRA force and monent time histories are obtained from the SMACK-derived estimates of accelerations and angular rates, and from ENCALderived estimates of weight and inertias. The body-axis forces are given by

$$
F_{x}=m a_{x} ; \quad F_{y}=m a_{y} ; \quad F_{, z}=m a_{z}
$$

where $m$ is vehicle mass. The moments are calculated from

$$
\begin{aligned}
& T_{l}=I_{x x} a_{l}-I_{z x}\left(a_{n}+p q\right)-\left(I_{y y}-I_{z z}\right) q r \\
& T_{m}=I_{y y} a_{m}-I_{z x}\left(r^{2}-p\right)-\left(I_{z z}-I_{x x}\right) p r \\
& T_{n}=I_{z z} a_{n}-I_{z x}\left(a_{l}-q r\right)-\left(I_{x x}-I_{y y}\right) p q \\
& \text { where } I_{x x}, I_{y y}, I_{z z}, I_{z x} \text { are vehicle moments of } \\
& \text { inertia. }
\end{aligned}
$$

\section{EXAMPLE MANEUVER}

The short takeoff-slow landing maneuver described earlier serves to illustrate the type of informa$t$ ion that is stored in the VSRA data base. In this maneuver, which contains abrupt changes in nozzle and flap angles, the aircraft transitions to normal flight after a short takeoff, performs a "go-around," and then transitions back to a STOL configuration for a slow landing. The raw data file includes all the onboard inertial and airdata, and radar tracking measurements indicated in Table 1. The variations in nozzle angle, flap setting, power, and control-surface positions required to perform the maneuver are shown in Fig. 5. Note how these time histories correlate with the activity requested of the pilot on the flight-test card of Fig. 3 .

The aircraft dynamic response to the control inputs is analyzed (along with the radar track) by the state-estimation procedure, which determines integrator initial conditions, selected instrument bias and scale-factor errors, and forcing-function time historles that provide the "best fits" to the measurement records $(R, B, E),(P, a, B),\left(a_{x}, a_{y}\right.$, $\left.a_{z}\right),(p, q, r)$, and $(\phi, \theta, \psi)$. The body angular accelerations $\left(a_{q}, a_{n}, a_{n}\right)$, true airspeed $(V)$, and flightpath winds ( $w_{x}, w_{y}, w_{h}$ ) are also estimated. Results of the SMACK analysis required for calculating forces and moments are shown in Fig. 6 .
In a final step, the aerodynamic forces and moments are calculated as the difference of total and engline forces and moments as outlined in the previous section. These are the time,histories that must be adequately represented by the VSRA aerodynamic model. Results of the ENCAL calculations for the maneuver are shown in F18. 7, with the corresponding aerodynamic variables shown in Fig. 8. Notice the tradeoff between engine and aerodynamic vertical forces during the STOL portlons of the maneuver.

\section{CONCLUDINC REMARKS}

This paper has described a flight-test methodology designed to generate a data base suitable for Identifying an aerodynamic model using a regression procedure. Test maneuvers were deslgned to provide large changes in state and control variables around nominal trim points. The technique of state estimation was used to produce a consistent data set and to provide estimates of unmeasured variables. The availabillty of an accurate engine model has made it possible to isolate engine effects and determine aerodynamic forces and moments.

The completed VSRA data base consists of the set of individual 3-5 min flight-test maneuvers that covers the required flight envelope. Long (15-30 min) records, consisting of concatenated time segments frow several maneuvers, can be created and used to ldentify parameters in each model section. An example of a typical maneuver In the data base has been shown in the paper. Work on developing the USRA aerodynamic model from the data base is now in progress.

\section{ACKNOHLEDGMENT}

The authors would like to thank programmers Mine Hagen and Suzi Kovacevich, and students Vafa Kordestani and Phil Solth for their contributions to the work reported in this paper. We are grateful to Tom Schultz for his work on the Pegasus engine model.

\section{APPENDIX: A STATE-ESTIMATION ALGORITHM}

In the context of this paper, "state estimation" refers to a process that solves a state model

$$
\dot{x}=f(x, w), \quad x\left(t_{0}\right)=x_{0}
$$

such that $h(x)$ in the measurement model

$$
z=h(x)+v
$$

suitably matches the data record over a time interval $\left(t_{0}, t_{f}\right)$, usually in a least-squared error or minimum-variance sense. In Eq. (A.1), $x$ Is the state vector and $w$ is a vector that represents any unknown forcing functions. In Eq. (A.2), $h(x)$ is the system output vector; $z$ and $v$ are vectors representing the measurements and corresponding (random) measurement errors.

For aircraft problems, the state and measurement models together represent the dynamics of a rigid 
sody. The models are used to generate time histories which include onboard variables such as Euler angles, angular rates, and linear accelerations, as well as tracking variables such as slant range, bearing, and elevation. Any bias or scale-factor errors associated with the state or measurement models are appended to the state vector and treated as constant but unknown parameters.

The task of postflight state estimation prior to modeling is considered as a fixed-interval smoothing problem. Its solution consists of determining the $x_{0}$ and $w(t)$ that minimize the squared-error performance measure

$$
\begin{aligned}
J= & \left(x_{0}-\bar{x}_{0}\right)^{t_{p}-1}\left(x_{0}-\bar{x}_{0}\right) / 2 \\
& +\int_{t_{0}}^{t_{f}}\left\{[z-h(x)]^{t_{R}-1}[z-h(x)]+w^{t} Q^{-1} w\right] d t / 2
\end{aligned}
$$

subject to the dynamic constraint of Eq. (A.1). In Eq. (A.3), $\bar{x}_{0}$ is an a priori estimate of $x_{0}$, and $P_{0}, Q^{\circ}$, and $R$ are weighting matrices. Note that the first term of $\mathrm{Eq}$. (A.3) serves as a "penalty" function and tends to blas the estimate of $x_{0}$ toward its a priori value.

The necessary conditions for minimizing the performance measure lead to a nonlinear, two-point boundary value problem which is solved using a successive-linearization approach. A good algo$r i$ thm involves choosing $x_{0}$ and $w$, solving Eqs. (A.1) and (A.2) to obtain a "nominal" solution, and then determining a change in the initial condition from

$$
\delta x_{0}=-\left(P_{0}^{-1}+M_{0}\right)^{-1}\left[P_{0}^{-1}\left(x_{0}-\bar{x}_{0}\right)+a_{0}\right)
$$

where $M_{0}$ and $a_{0}$ are found by solving (backwards in time) the "information" filter

$$
\begin{aligned}
\dot{M} & =-f_{x}^{t_{M}}-M f_{x}-h_{x}^{t_{R}-1_{h}}+M f_{w} Q f_{w}^{t_{M}} \\
\dot{a} & =-f_{x}^{t_{a}}+h_{x}^{t_{R}-1}[z-h(x)]+M f_{w}\left(Q f_{w}^{t} a+w\right) \\
M\left(t_{f}\right) & =0, \quad a\left(t_{f}\right)=0 \\
M_{0} & =M\left(t_{0}\right), \quad a_{0}=a\left(t_{0}\right)
\end{aligned}
$$

In Eq. (A.5), $M$ is the "Information" matrix and $a$ is the "gradient" vector, and $f_{x}, f_{w}$, and $h_{x}$ are Jacobian matrices.

Next, a change in the forcing function is determined by solving (forward in time) a first-order expansion of the dynamic constraint

$$
\begin{aligned}
& \delta \dot{x}=f_{x} \delta x+f_{w} \delta w, \quad \delta x\left(t_{0}\right)=\delta x_{0} \\
& w i t h \quad \delta w=-w-a f_{w}^{t}(a+M \delta x)
\end{aligned}
$$

The procedure is iterated until the performance measure of Eq. (A.3) is minimized. It can be shown (Bach, 1977) that this algorithm is equivalent to the "modified" Newton-Raphson algorithm if there are no unknown forcing functions.

\section{REFERENCES}

Anderson, L.C. (1986). AV-8B Systew Ident1flcation Results: Lateral-Directional Model, Ground Effects, and High Angle-or-Attack Model, Systems.

Anderson, L.C., and Bunnell, J.H. (1985). AV-8B Simulation Model Engineering Specification (Version 2.2), Systems Control Technology, Inc.

Anderson, L.C., and Hansen, R.S. (1987). Review of AV-8B Aerodynamic Model Identification, SCT Report (ARC PO A46963C).

Anon. (1983). YAV-8B Simulation and Modelling, Vol. 1: Alrcraft Description and Program Sumary, NASA CR-170397.

Bach, R.E., Jr.: (1977). Variational Algorithms for Nonlinear Smoothing Applications, NASA TM-73211.

Bach, R.E., Jr.: (1982). A Variational Technique for Smoothing Flight-Test and Accident Data, AIAA Journal of Aircraft, 19, $7: 546-552$.

Bach, R.E., Jr., and Wingrove, R.C. (1985). Applications of State Estimation in Aircraft Flight-Data Analysis, AIAA Journal of Aircraft, 22, 7: 547-554.

Draper, N.R., and Smith, H. (1981). Applied Regression Analysis, John Wiley and Sons, Inc., New York, Chap. 6.

Dunlap, E.H., and Porter, M.B. (1971). Theory of the Measurement and Standardization of In-Flight Performance of Aircraft, AFFTC TD-71-1.

Eranklin, J.A. (1987). USRA Air Data Calibration, Internal Memorandum.

Gainer, T.G., and Hoffman, S. (1972). Summary of Transformation Equations and Equations of Motion Used in Free-Flight and Wind-Tunnel Data Reduction and Analysis, NASA SP-3070.

Gerlach, O.H. (1966). Determination of Performance, Stability and Control Characteristics from Measurements in Nonsteady Maneuvers, AGARD CP-17, Part 1, pp. 499-523.

Hansen, R.S. (1979). DEKFIS User's Guide - Discrete Extended Kalman Filter/Smoother Program for Alreraft and Rotorcraft Data Consistency, NASA CR-159081.

Klein, V., and Batterson, J.G. (1983). Determ1nation of Alrplane Model Structure from Flight Data Using Splines and Stepwise Regression, NASA TP-2126.

Klein, V., and Batterson, J.G. (1986). Aerodynamic Parameters Estimated from Flight and Wind-Tunnel Data, AIAA Journal of Alrcraft, 23, 4: 306-312.

Klein, V., and Schiess, J.R. (1977). Compatibil-. Ity Check of Measured Aircraft Responses Using Kinematic Equations and an Extended Kalman Filter, NASA TN D-8514.

MoNally, B.D. (1986). Eull-Envelope Aerodynamic Modeling of the Harrier Aircraft, NASA TM-88376.

Sri-Jayantha, M., and Stengel, R.F. (1983). Data Acquisition System and Methodology for High Angle of Attack Parameter Estimation, SAE Paper No. 830719.

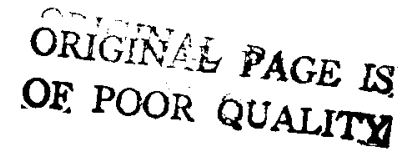


Stalford, H.L., and Ramachandran, S. (1978). Application of the Estimation-BeforeModelling (EBM) System Identiflcation Method to the High Angle-of-Attack/Sideslip Flight of $\mathrm{T}-2 \mathrm{C}$ Jet Trainer Aircraft, NADC-76097-30.
Wingrove, R.C. (1973). Quasilinearization Technique for Estimating Aircraft States from Flight Data, AIAA Journal of Aircraft, 10, 5: 303-307.

TABLE 1 Variable List for Aerodynamic Model Data Base

\begin{tabular}{lll}
\hline \multicolumn{1}{c}{ Channel } & Measured & Estimated \\
Euler Angles & Onboard & SMACK \\
Angular Rates & Onboard & SMACK \\
Angular Accelerations & & SMACK \\
Linear Accelerations & Onboard & SMACK \\
Positions wrt Earth & Radar & SMACK \\
Velocities wrt Earth & & SMACK \\
Air-flow Angles & Onboard & SMACK \\
Static Pressure & Onboard & \\
Total Pressure & Onboard & SMACK \\
Total Temperature & Onboard & \\
True Airspeed & & SMACK \\
Flightpath Winds & SMACK \\
Flap Setting & & \\
Alleron Deflections & Onboard & \\
Stabilator Deflection & Onboard & \\
Rudder Deflection & Onboard \\
Engine Nozzle Angle & Onboard \\
Engine Fan Speed & Onboard \\
Compressor Pressure & Onboard \\
Fuel and Water Weights & Onboard \\
RCS Roll-Valve Positions & Onboard \\
RCS Pitch-Valve Positions & Onboard \\
RCS Yaw-Valve Position & Onboard \\
Engine and RCS Body Forces & Onboard \\
Engine and RCS Moments & & \\
Gross Weight and Inertias & & ENCAL \\
\hline
\end{tabular}

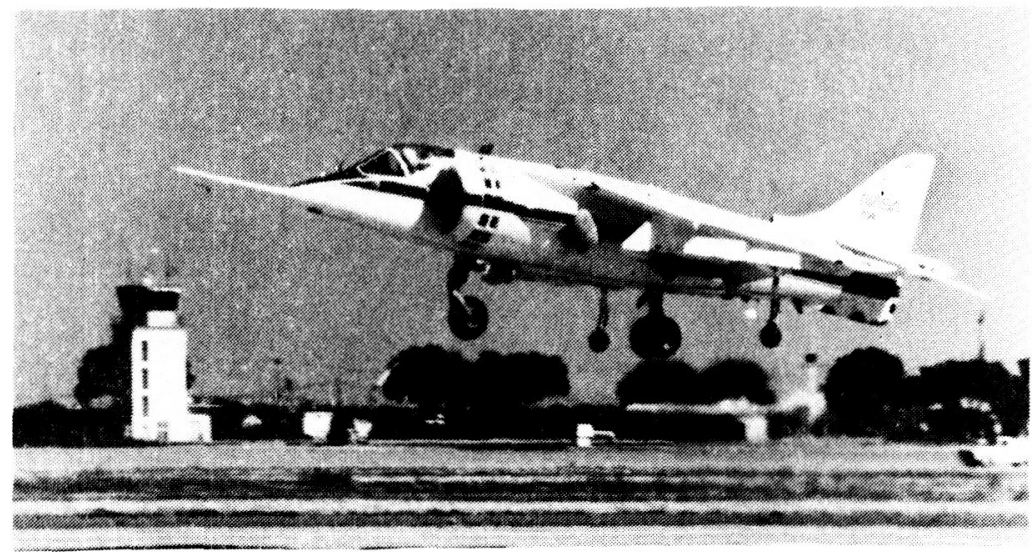

Fig. 1. The NASA V/STOL Research Aircraft (VSRA). 


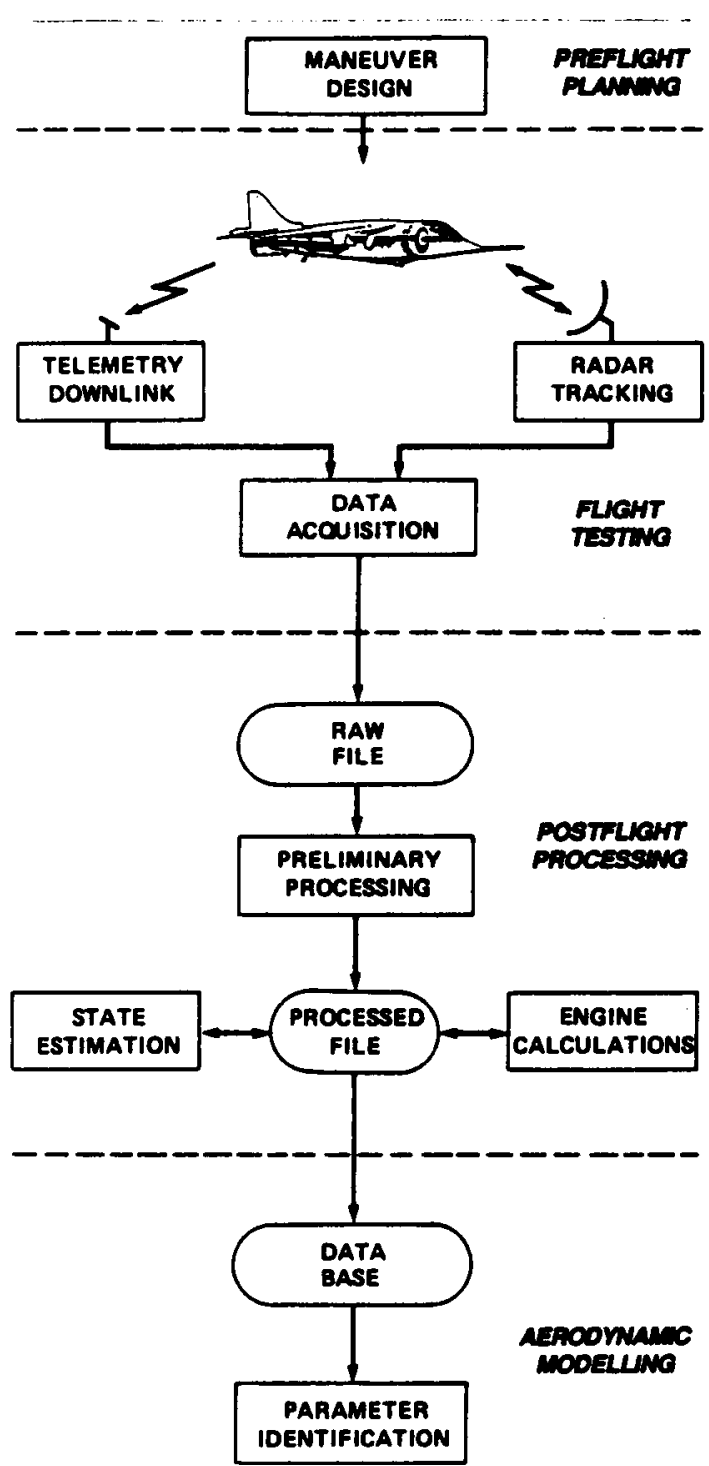

Fig. 2. Flow diagram for VSRA flight-test methodology.
FUGHT TEST CARD

SHORT TAKEOFF - SLOW LANDING

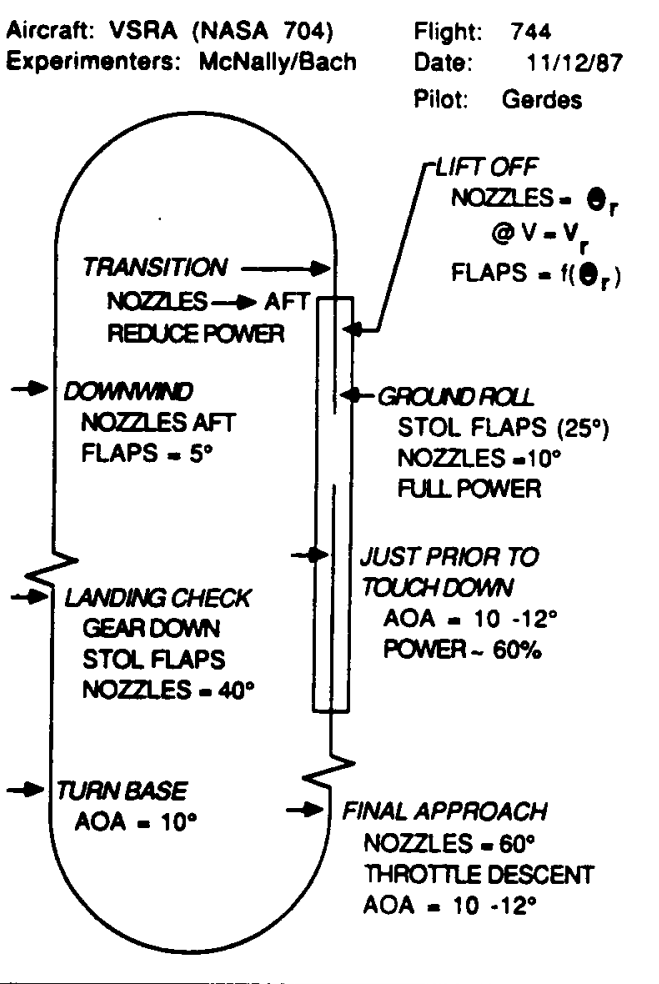

Fig. 3. Plan view of STOL Maneuver.

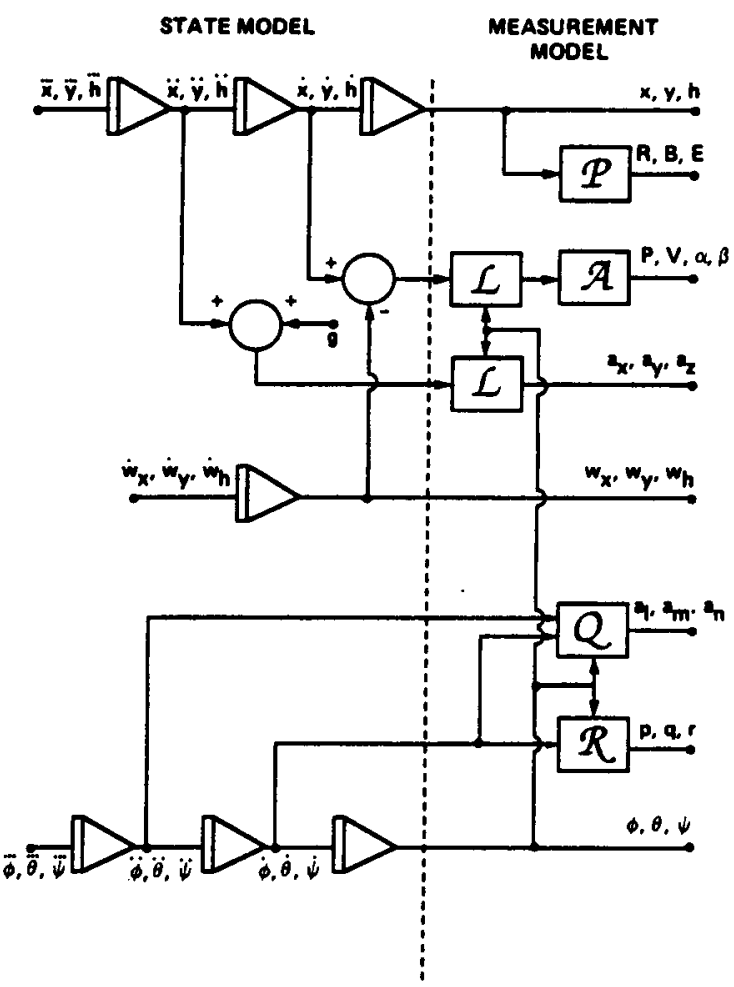

F1g. 4. State and measurement models for the SMACK state-estimation procedure. 

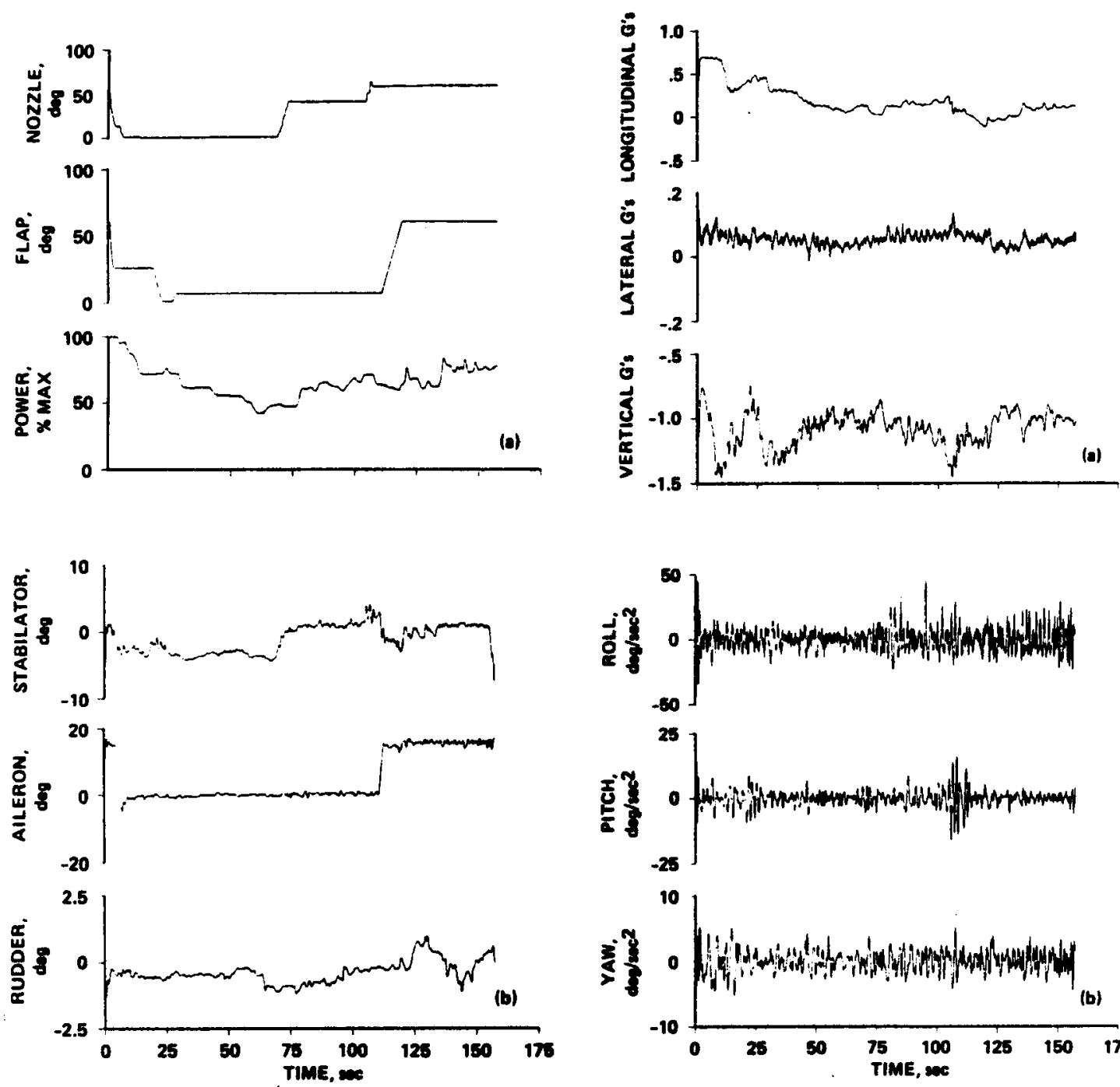

Fig. 5. Control time histories for STOL maneuver. (a) Nozzle, flap, power. (b) Stabilator, aileron, rudder.
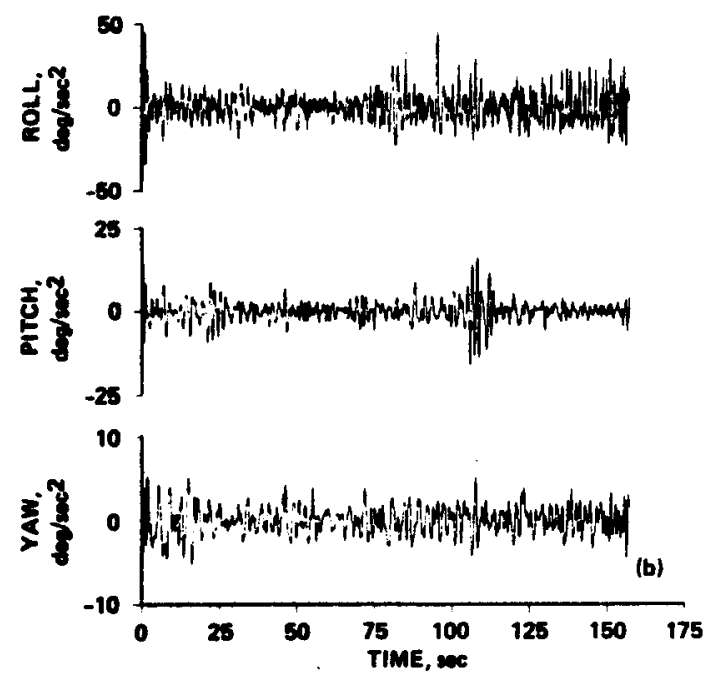

Fig. 6. SMaCK estimates for STOL maneuver.

(a) IInear accelerations. (b) Angular accelerations. 

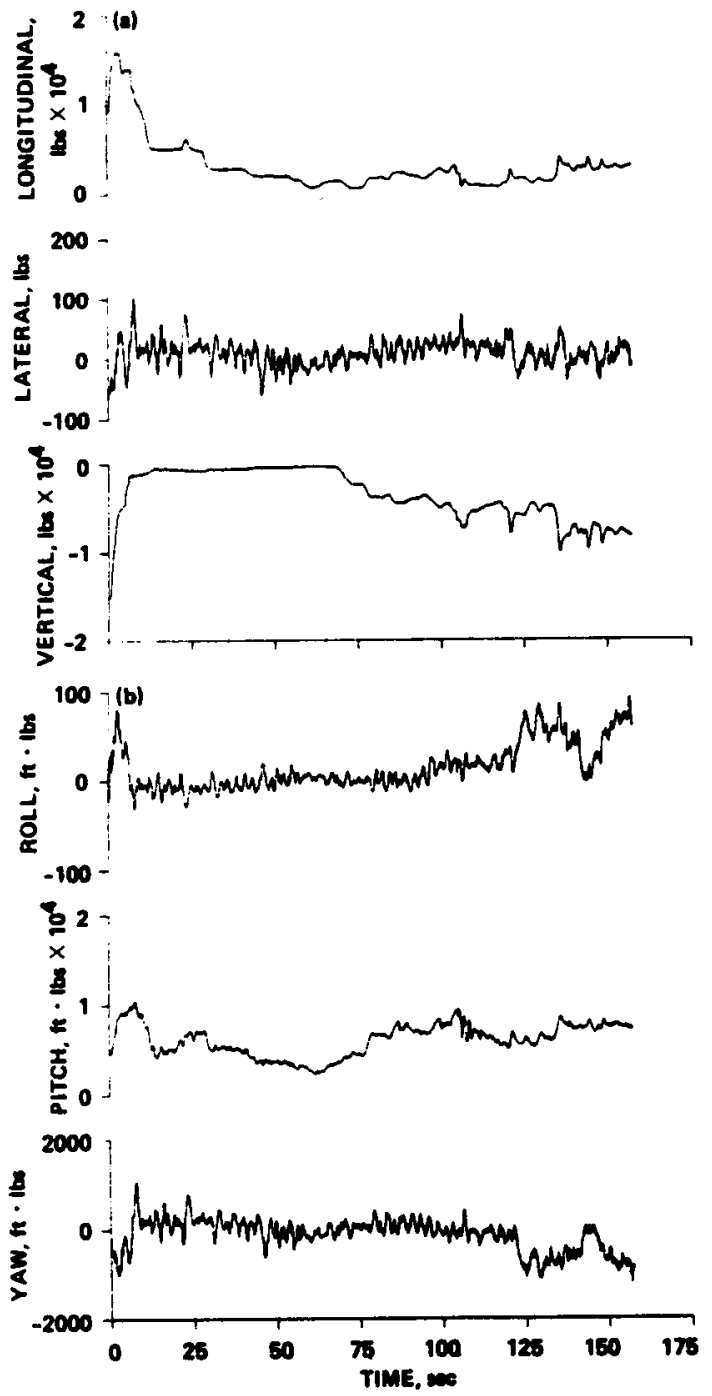

Fig. 7. ENCAL estimates for STOL maneuver. (a) Engine forces. (b) Engine moments.
ORIGINAL PAGE IS
OF POOR MUAEITY
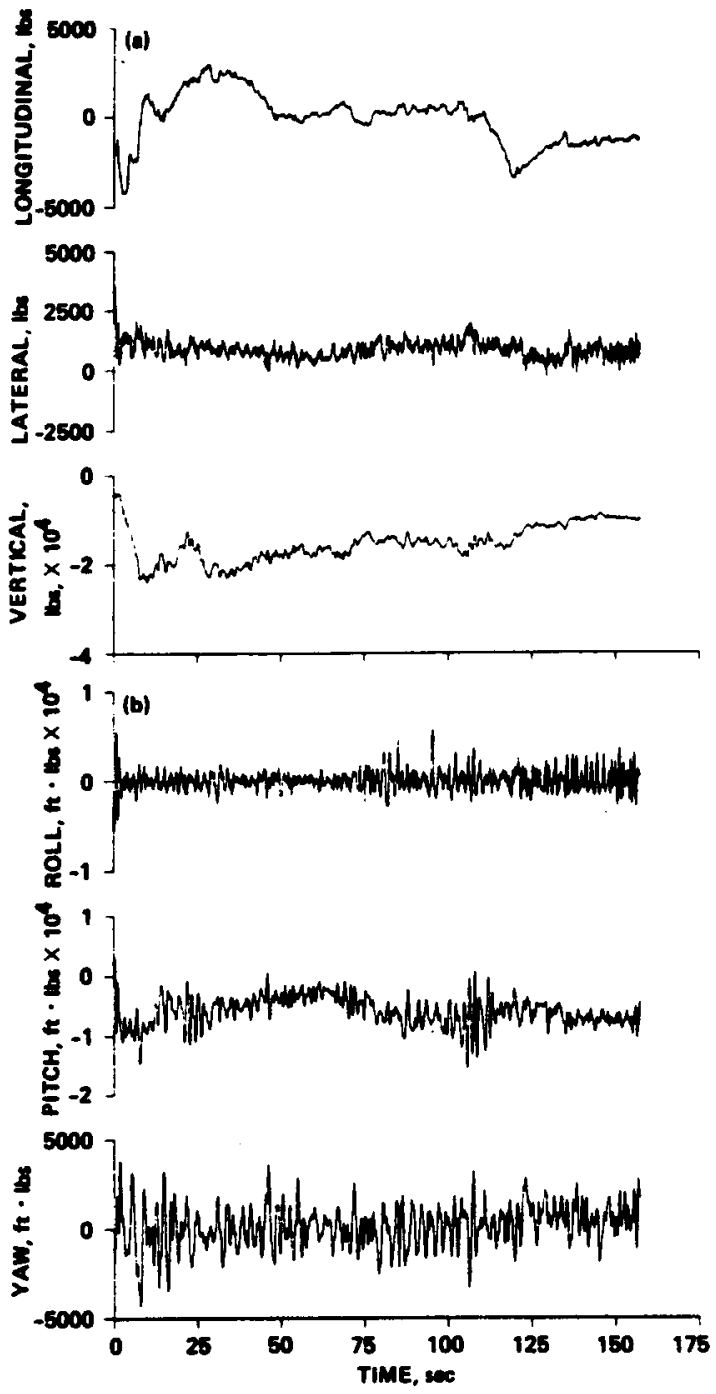

Fig. 8. Aerodynamic variables for STOL maneuver. (a) Body forces. (b) Monents. 


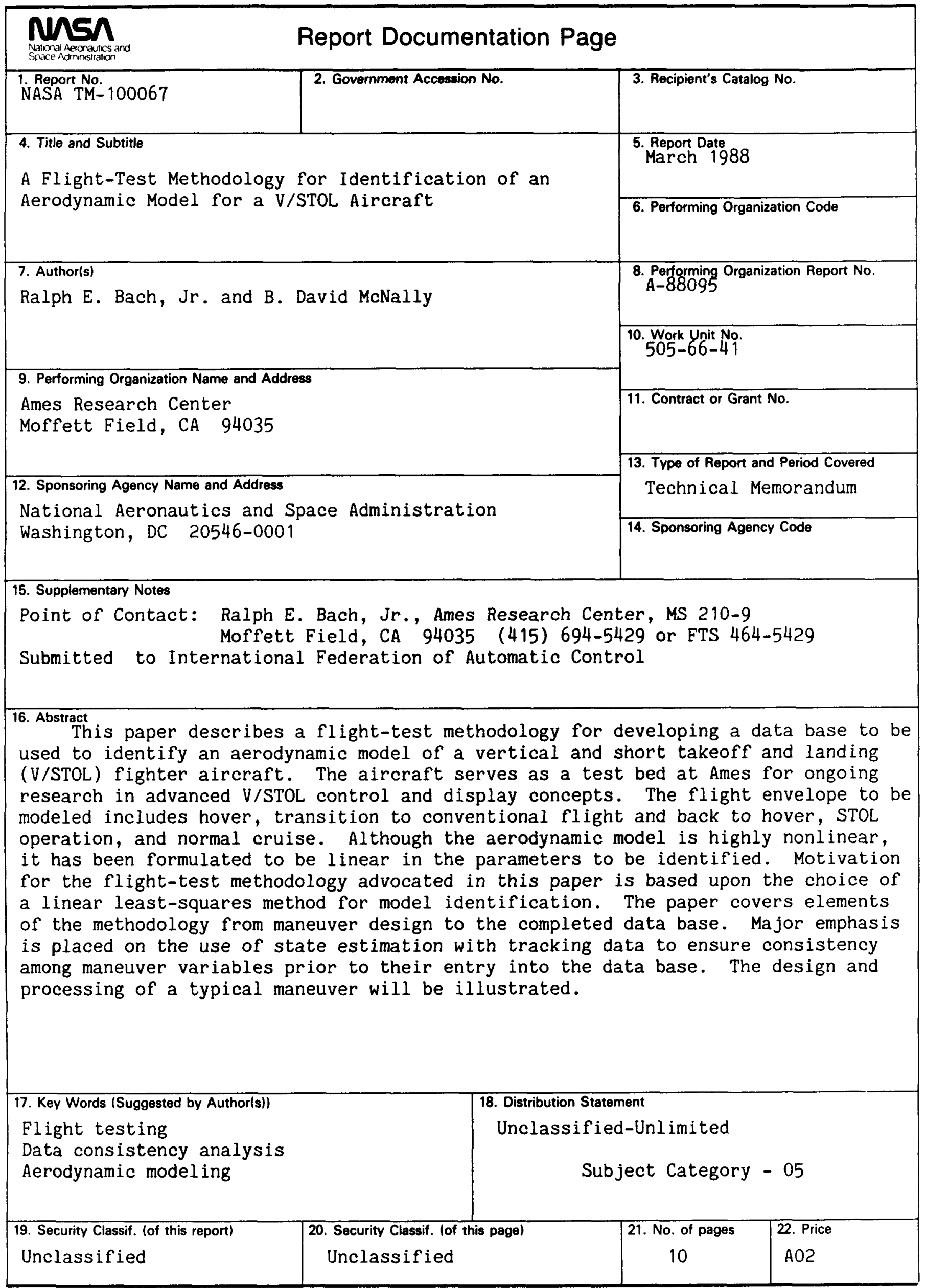

